\title{
Nephroprotective and Anti-inflammatory Effects of Aqueous Extract of Melissa officinalis L. on Acetaminophen-induced and Pleurisy-induced Lesions in Rats
}

\author{
Denise Pereira Müzell ${ }^{1}$, Adroaldo Lunardelli ${ }^{2}$, Carlos Eduardo Leite ${ }^{3}$, Rodrigo Medeiros \\ Fagundes $^{2}$, Vasyl Custódio Saciura ${ }^{2}$, Carlos Luiz Reichel ${ }^{4}$, Jarbas Rodrigues de Oliveira ${ }^{2 *}$ \\ and Leandro Vieira Astarita ${ }^{1}$ \\ ${ }^{1}$ Laboratório de Biotecnologia Vegetal; ${ }^{2}$ Laboratório de Pesquisa em Biofísica Celular e Inflamação; ${ }^{3}$ Instituto de \\ Toxicologia; ${ }^{4}$ Laboratório de Anatomia Patológica; Pontifícia Universidade Católica do Rio Grande do Sul; Av. \\ Ipiranga 6681; 90619-900; Porto Alegre - RS - Brasil
}

\begin{abstract}
This study assessed the bioactive properties of an aqueous extract of $\mathrm{M}$. officinalis for its anti-inflammatory activity and its protection against hepatic and renal lesions induced by acetaminophen (APAP). Animals pre-treated with the crude extract in pleurisy induced by carrageenan showed a reduction in the amounts of exudate, in the numbers of leukocytes and polymorphonuclear cells. Intragastric administration of the extract for seven days prior to the APAP-induced lesion showed no protective effect on the liver. The treatment with the extract induced an increase of serum aspartate aminotransferase, indicating a rise of toxicity. Contrarily, the same treatment reduced the APAPinduced lesion in kidney, with respect to $\gamma$-glutamyltransferase. The results suggested that the extract was not hepatoprotective and could lead to an increase in the lesions induced by the APAP. On the other hand, the extract was nephroprotective against the lesions induced by the APAP and showed an anti-inflammatory effect on pleurisy carrageenan-induced.
\end{abstract}

Key words: Acetaminophen, Melissa officinalis, pleurisy, anti-inflammatory, kidney, liver

\section{INTRODUCTION}

In recent years, interest in medicinal herbs has been growing worldwide, particularly in Brazil. Despite the great biodiversity of the family Lamiaceae in Brazil, approximately $75 \%$ of Lamiaceae species cultivated as medicinal herbs in southern Brazil are exotic, namely Melissa officinalis (L.), Rosmarinus officinalis (L.), Origanum $x$ applii (Domin) Boros and Mentha $x$ rotundifolia (L.) Huds (Garlet and Irgang 2001). A number of studies have demonstrated the hepatic and renal protective effect of the species of Lamiaceae, with pharmacological properties attributed to the main constituents, such as rosmarinic acid, essential oils and phenolic compounds. The infusion of $M$. officinalis leaves has been widely used in folk medicine, because of its sedative and antispasmodic properties and gastrointestinal disorders.

Several species of Lamiaceae, such as Perilla frutescens and Salvia leriifolia, have shown antiinflammatory activity (Hosseinzadeh et al. 2003; Osakabe 2004). Traditional herbal remedies have been used for centuries to alleviate the inflammatory conditions. Among the constituents of plant bioactive extracts, the phenolic compounds have a recognized hepatoprotective

*Author for correspondence: jarbas@pucrs.br 
and anti-inflammatory action. Rosmarinic acid and flavonoids inhibit several enzymes involved in the inflammatory process, such as monooxygenase, lipooxygenase and cyclooxygenase (Petersen and Simmonds 2003; Svobodová et al. 2003). On the other hand, some flavonoids, such as epigallocatechin gallate, found in green tea, and phenolic compounds may induce hepatotoxicity in mice (Galati and O'brien 2004). Likewise, the tincture of Salvia officinalis significantly reduced the total percentages of leukocytes and monocytes in bone marrow (Oniga et al. 2007).

Extracts from the leaves of Rosmarinus officinalis showed a dose-dependent anti-inflammatory activity (Altinier et al. 2007). Several studies have described the medicinal properties of species of Lamiaceae. Animals pretreated with a leaf extract of Mentha piperita showed an increase in the activities of the enzymes superoxide dismutase and catalase, and a decrease in the formation of malondialdehyde in liver exposed to gamma radiation (Samarth et al. 2006). Although Mentha spicata caused markedly nephrotoxic changes in the rats, extracts of Mentha piperita had no effect (Akdogan et al. 2003). Mice pretreated with Origanum majorana and exposed to lead showed a reduction in the activities of aspartate aminotransferase and alanine aminotransferase, as well as urea and creatinine (El-Ashmawy et al. 2005). Extracts of another species of Lamiaceae, Rosmarinus tomentosus, prevented cirrhosis induced by thioacetamide (Galisteo et al. 2006). Rosmarinus officinalis has also been reported to preserve the cellular integrity and limit the severity of carbon tetrachloride-induced injury. Similarly, it has been reported that the extracts of this medicinal herb accelerate the recovery of glycogen stores and stimulate the activity of glutathione $S$ transferase in liver (Sotelo-Félix et al. 2002).

Melissa officinalis is a well-known medicinal plant. This species shows high levels of polyphenols, which represent the fraction of phenolic compounds with the highest biological activity (Petersen and Simmonds, 2003). Extracts and constituents from $M$. officinalis have been well documented. Dried leaves contain 0.02-0.8\% essential oil (with the main components being citral and citronellal) and $11.8 \%$ of total polyphenol compounds comprising total hydroxycinnamic compounds $11.3 \%$ (rosmarinic acid $4.1 \%$ ) and total flavonoid compounds $0.5 \%$ (Carnat et al. 1998).
The experiments with inflammation can be carried out using different drugs, such as carrageenan, a polysaccharide that causes a reproducible inflammatory reaction and remains the standard irritant for examining the acute inflammation and anti-inflammatory drugs. Otherwise, hepatic and renal lesions can be experimentally induced by acetaminophen. Acetaminophen (APAP), commonly known as paracetamol, is widely used as an analgesic and antipyretic drug, and can be found either in pure formulations or as a constituent in a number of medicines. The consumption of high doses of this drug can cause centrolobular hepatic necrosis, as it is a powerful hepatotoxic agent (Lin et al. 2000). In addition, it can lead to renal necrosis in the proximal tubule, with a significant reduction in glomerular filtration (Bessems and Vermeulen 2001).

Hepatic lesion caused by the APAP is associated not only with high doses, but also with chronic use at low concentrations, particularly in the presence of other pre-disposing factors, such as chronic alcohol consumption, periods of fasting, and drugto-drug interaction during prolonged treatment. In spite of the wide use of Melissa in folk medicine in Brazil, few studies on the protective effect of the crude extract on the liver and kidney and its anti-inflammatory effect are available. The objective of this study was to evaluate the antiinflammatory activity of a crude aqueous extract of $M$. officinalis (L.) in pleurisy induced by carrageenan and to assess its effects in the protection against hepatic and renal lesions induced by acetaminophen.

\section{MATERIALS AND METHODS}

\section{Plant material}

Plants of Melissa officinalis (L.) were cultivated in the pots with regular watering and a natural photoperiod. The plants were taken to the laboratory 15 days prior to the onset of the experiments, and kept at $25 \pm 2^{\circ} \mathrm{C}$ with a 16 -h photoperiod. Samples of the leaves $(50 \mathrm{~g})$ were homogenized with distilled water $(1: 5 \mathrm{w} / \mathrm{v})$. The extract was filtered on the paper with the aid of a vacuum pump, and then centrifuged at $15^{\circ} \mathrm{C}$ for 15 minutes at $4500 \mathrm{x} g$. The supernatant was stored at $-20^{\circ} \mathrm{C}$. Prior to use, the extract was analyzed in order to quantify its quercetin-derived components (total phenolics and flavonoids). 


\section{Animals}

A controlled experimental study was conducted using Wistar albino rats (Rattus norvegicus). The animals were kept on the shelves with ventilated cages that provide 60 air cycles per hour, a relative humidity ranging between $55-65 \%$, a $12 \mathrm{~h}$ lightdark cycle, a temperature of $22 \pm 2{ }^{\circ} \mathrm{C}$ with free access to food and water. The animals were maintained in accordance with the "Guiding Principles in the Care and Use of Animals" by the Council of the American Physiological Society. The experimental protocol was approved by the Ethics Research Committee of Pontifícia Universidade Católica do Rio Grande do Sul (PUCRS).

\section{Carrageenan-induced pleurisy}

The pleurisy was induced by the injection of 0.2 $\mathrm{mL}$ of sterile saline solution $(\mathrm{NaCl} 0.9 \%)$ containing carrageenan (1\%) (Sigma Chemical) into the right pleural space of female rats (weighing 200-250 g) under anesthesia (Paul et al. 2009). The animals were euthanized $4 \mathrm{~h}$ later in a $\mathrm{CO}_{2}$ chamber. The chest was then carefully opened and the pleural cavity was rinsed with $2.0 \mathrm{~mL}$ of saline solution containing 1\% EDTA (Boschi et al. 2008). The exudates and rinse solution were removed by aspiration and the total volume was measured. The exudates contaminated with blood were discarded (Spiller et al. 2008). The amount of exudates was calculated by subtracting the volume injected $(2.0 \mathrm{~mL})$ from the total volume recovered (Santos et al. 2010). Total leukocytes were diluted in Thoma solution (1:20) and counted in a Neubauer chamber using light microscopy. Cytological slide smears stained with MayGrünwald/Giemsa were used for differential leukocyte counts in a light microscope (Lunardelli et al. 2006). The plasma exudation was determined by protein concentration exudate. The exudate obtained from the pleural cavity was centrifuged at $1200 \times g$ for 10 minutes and the total protein content of the supernatant measured spectrophotometrically using the Biuret technique (Lopes et al. 2006).

In the treatment groups, animals were intraperitoneally (i.p.) injected in the bolus (acute therapy) 30 minutes before the carrageenaninduced pleurisy with the extracts of $M$. officinalis at concentrations of 50,100 and $200 \mathrm{mg} / \mathrm{kg}$ in a final volume of $1.0 \mathrm{~mL}$. In the inflammation group, saline solution was injected i.p. 30 minutes before the intrapleural (i.pl.) carrageenan injection.
Control animals were injected both i.p. and i.pl. with saline solution. The experiments were performed on different days and the total number of animals per group was six.

\section{Hepatotoxicity of APAP}

Male rats (weighing 215 to $300 \mathrm{~g}$ ) were treated intraperitoneally with different concentrations of APAP $(300,650,800,1000$ or $1500 \mathrm{mg} / \mathrm{kg})$ in order to determine its toxicity and the survival curve ( $\mathrm{n}=10$ for each group). Alanine aminotransferase (ALT), aspartate aminotransferase (AST) activity and mortality were evaluated $24 \mathrm{~h}$ after the administration of APAP. Saline administration was used as the control treatment. Kaplan-Meier test was used to investigate the survival.

\section{Administration of extracts}

Male rats (weighing 215 to $300 \mathrm{~g}$ ) were pre-treated intragastrically (i.g.) for seven days with 5.0 $\mathrm{mL} / \mathrm{kg}$ per day of saline solution or the aqueous extract of $M$. officinalis. Considering the interactions that might occur at the digestive level between polyphenols and other dietary nutrients, reducing the intestinal absorption (Silberberg et al. 2006), the extract was administered intragastrically at a concentration of $500 \mathrm{mg} / \mathrm{kg}$ $(1: 10 \mathrm{w} / \mathrm{v})$. This concentration was 2.5 fold higher than the concentration administered intraperitoneally in the pleurisy experiment.

On the sixth day of the pre-treatment, the animals were transferred to metabolic cages and maintained under this condition for $48 \mathrm{~h}$. Immediately after the last intragastric administration of the pre-treatment, the APAP $(800 \mathrm{mg} / \mathrm{kg}-4 \mathrm{~mL} / \mathrm{kg}$ ), or saline solution (control treatment) were administered intraperitoneally. Blood samples were collected from the animals 24 $\mathrm{h}$ after the treatment with APAP or saline solution through retro-orbital sinus puncture. The samples were centrifuged at $1500 \mathrm{xg}$ for 15 minutes. Urine samples were also collected from the animals during 24 hours after the treatment with APAP or saline solution. Urine samples were centrifuged at $500 \mathrm{x}$ g for 10 minutes.

The animals were divided into four groups (pretreated i.g. for seven days + treated i.p.), in the following manner: group saline + saline; group saline + APAP; group extract + saline; group extract + APAP. The experiments were performed on different days and the total number of animals per group was six. 
The hepatotoxicity of the APAP was assessed by the analysis of the biochemical markers ALT and AST in serum. The analyses were carried out according to a previously described procedure (Schumann et al. 2002ab; Schumann et al. 2010). The renal injury was analyzed through the urinary excretion of $\gamma$-glutamyltransferase (GGT). Quantification was performed by the kinetic method according to a previously described procedure (Schumann et al. 2002c; Schumann et al. 2010). Subsequently, the GGT activity was calculated in relation to the urinary volume in $24 \mathrm{~h}$.

Table 1 - Effects of $M$. officinalis (50, 100 and $200 \mathrm{mg} / \mathrm{Kg}$ ) on exudate volume, total leukocytes, polymorphonuclear leukocytes (PMNs) and total protein in the pleural cavity in carrageenan-induced pleurisy. Results are expressed as mean \pm SEM. The different letters on column indicate differences $(\mathrm{P}<0.05)$.

\begin{tabular}{|c|c|c|c|c|}
\hline & Volume $(\mathrm{mL})$ & Leukocyte (x10\%/cavity) & PMNs (x10\%/cavity) & Protein $(\mathrm{g} / \mathrm{dL})$ \\
\hline Control & $0.07 \pm 0.02^{\mathrm{d}}$ & $10.57 \pm 1.04^{\mathrm{c}}$ & $3.12 \pm 0.15^{\mathrm{d}}$ & $0.17 \pm 0.05^{\mathrm{c}}$ \\
\hline Inflammation & $0.85 \pm 0.05^{\mathrm{a}}$ & $46.18 \pm 1.19^{\mathrm{a}}$ & $42.46 \pm 0.99^{\mathrm{a}}$ & $1.55 \pm 0.05^{\mathrm{a}}$ \\
\hline $50 \mathrm{mg} / \mathrm{Kg}$ & $0.83 \pm 0.07^{\mathrm{a}}$ & $41.33 \pm 1.63^{\mathrm{b}}$ & $37.36 \pm 1.64^{\mathrm{a}}$ & $1.53 \pm 0.05^{\mathrm{a}}$ \\
\hline $100 \mathrm{mg} / \mathrm{Kg}$ & $0.55 \pm 0.08^{\mathrm{b}}$ & $30.56 \pm 2.39^{\mathrm{b}}$ & $26.23 \pm 2.06^{\mathrm{b}}$ & $1.52 \pm 0.05^{\mathrm{ab}}$ \\
\hline $200 \mathrm{mg} / \mathrm{Kg}$ & $0.34 \pm 0.06^{\mathrm{c}}$ & $22.14 \pm 2.20^{\mathrm{b}}$ & $18.57 \pm 1.87^{\mathrm{c}}$ & $1.34 \pm 0.05^{\mathrm{b}}$ \\
\hline
\end{tabular}

\section{Quantification of the extract compound}

Phenolic compound levels were assessed by the colorimetric reaction using Folin-Ciocaulteau reagent and $20 \% \quad \mathrm{Na}_{2} \mathrm{CO}_{3}$. The absorbance (765 $\mathrm{nm}$ ) was determined in a spectrophotometer after 30 minutes incubation at $25^{\circ} \mathrm{C}$ in the dark. Gallic acid was used as the standard in order to establish the calibration curve, which ranged from 0.25 to $0.0078 \mathrm{mg} / \mathrm{mL}(\mathrm{r}=0.996)$.

The levels of quercetin-derived flavonoids were determined by the colorimetric technique, using the reaction with $96 \%$ ethanol, $10 \%$ aluminium nitrate and $1 \mathrm{M}$ potassium acetate. The absorbance was determined in a spectrophotometer $(415 \mathrm{~nm})$ after 5 minutes. Quercetin was used as a standard in order to establish the calibration curve, which ranged from 0.125 to $0.0039 \mathrm{mg} / \mathrm{mL}(\mathrm{r}=0.999)$. The flavonoid content was expressed as $\mathrm{mg}$ quercetin equivalents/g FW.

\section{Statistical analysis}

The results were statistically evaluated through the analysis of variance (ANOVA) with a LSD post hoc test using the SPSS (Statistical Package for the Social Sciences) 18.0 software and expressed as the mean \pm standard error of mean (SEM). The level of statistical significance was defined as P < 0.05 .

\section{RESULTS}

The aqueous extracts of Melissa officinalis contained high levels of phenolic compounds $(0.35$
$\% \mathrm{FW})$ and flavonoids $(0.14 \% \mathrm{FW})$. In the 500 $\mathrm{mg}$ of extract, there were $1.25 \mathrm{mg}$ and $0.5 \mathrm{mg}$ of phenolic compounds and flavonoids, respectively. More than $95 \%$ of the total polyphenol compounds in the lemon balm are hydroxycinamic compounds (Carnat et al. 1998), representing approximately $1.19 \mathrm{mg}$ hydroxycinamic in $500 \mathrm{mg}$ of the extract. The administration of carrageenan induced an inflammatory response, which resulted in an increase in the volume of the exudate and leukocyte migration $(\mathrm{P}<0.05)$ compared with the control group. Similarly, polymorphonuclear cells (PMNs) and total protein concentration in the exudate were significantly increased $(\mathrm{P}<0.05)$ compared with the control. The groups of animals pre-treated with 200 and $100 \mathrm{mg} / \mathrm{kg}$ of the extract followed by the injection of carrageenan showed a reduction in the amounts of the exudate (60 and $35.3 \%$, respectively) (Table 1), in the numbers of leukocytes (52 and $33.82 \%$, respectively) and polymorphonuclear cells (56.26 and $38.22 \%$, respectively). However, in the groups of animals pre-treated with $50 \mathrm{mg} / \mathrm{kg}$, the parameters analyzed, except the leukocytes, were unaffected. The extract at a concentration of $200 \mathrm{mg} / \mathrm{kg}$ caused a reduction in the total proteins $(13.55 \%)$, whereas the concentrations of 100 and $50 \mathrm{mg} / \mathrm{kg}$ had no effect on the total protein in the pleural exudate, compared with the carrageenan group (Table 1).

The hepatotoxic effect of the APAP was concentration-dependent. Concentrations higher than $650 \mathrm{mg}$ of the APAP led to a drastic increment in the ALT and AST levels (Fig.1) and 
caused animal death (Fig. 2). The concentration of $800 \mathrm{mg}$ of the APAP was considered as the sublethal dose, and therefore, it was used for inducing the hepatic lesion.

With respect to the hepatic lesion, no significant differences were observed in the levels of AST $(67 \pm 1.65 \mathrm{U} / \mathrm{L})$ and ALT $(24.7 \pm 1.98 \mathrm{U} / \mathrm{L})$, compared to the extract + saline to the saline + saline (Figures 3A and 3B). This result indicated that the aqueous extract of $M$. officinalis was not hepatotoxic. The levels of AST and ALT in the saline + APAP group $(122.1 \pm 5.08 \mathrm{U} / \mathrm{L}$ and $47 \pm 3.69 \mathrm{U} / \mathrm{L}$, respectively) were significantly higher than those observed in the saline + saline group $(72.5 \pm 2.57 \mathrm{U} / \mathrm{L}$ and $23.0 \pm 1.21 \mathrm{U} / \mathrm{L}$, respectively) (Figures $3 \mathrm{~A}$ and $3 \mathrm{~B}$ ). The pretreatment with the aqueous extract of $M$. officinalis did not reveal any hepatotoxic effects, when saline was used as the treatment. The levels of AST and ALT in this group $(67.0 \pm 1.65 \mathrm{U} / \mathrm{L}$ and $24.66 \pm 1.98$ $\mathrm{U} / \mathrm{L}$, respectively) did not differ from those observed in the saline + saline group (Figures $3 \mathrm{~A}$ and $3 \mathrm{~B}$ ). However, when the animals were pretreated with the extracts of $M$. officinalis and afterwards treated with the APAP, the levels of AST $(168.8 \pm 4.82 \mathrm{U} / \mathrm{L})$ and ALT $(55.2 \pm 16.72 \mathrm{U} / \mathrm{L})$ were increased, compared with the saline group.

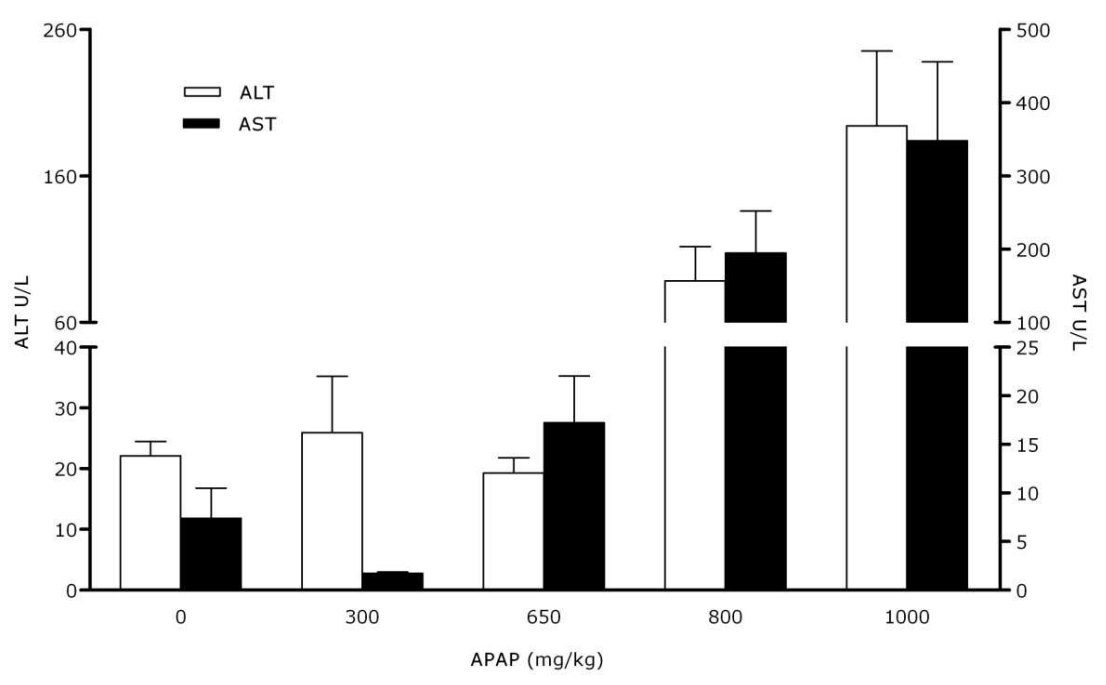

Figure 1 - Aspartate aminotransferase (AST) and alanine aminotransferase (ALT) activity in the serum of rats treated with intraperitoneal administration of acetaminophen (APAP) in different doses. Results are expressed as means and the vertical bars show the SEM.

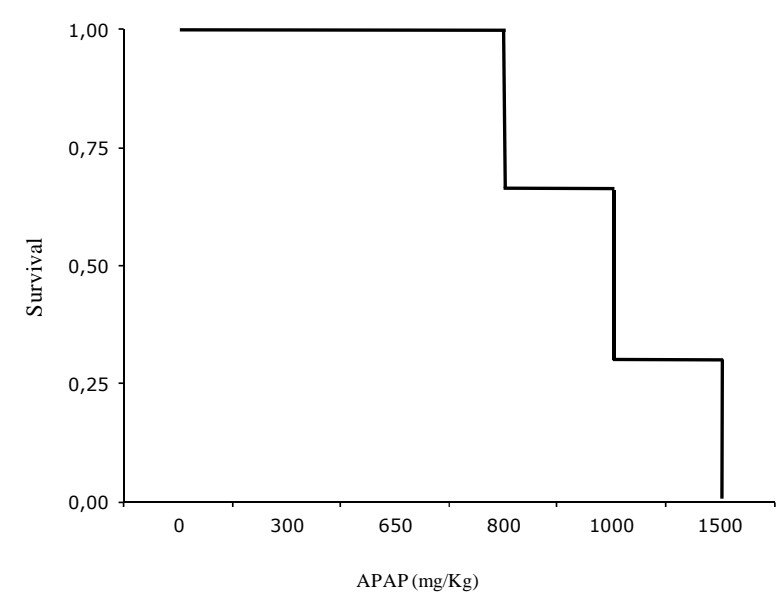

Figure 2 - Curve that relates the mortality to the acetaminophen (APAP) dose (Kaplan-Meier survival curve). 

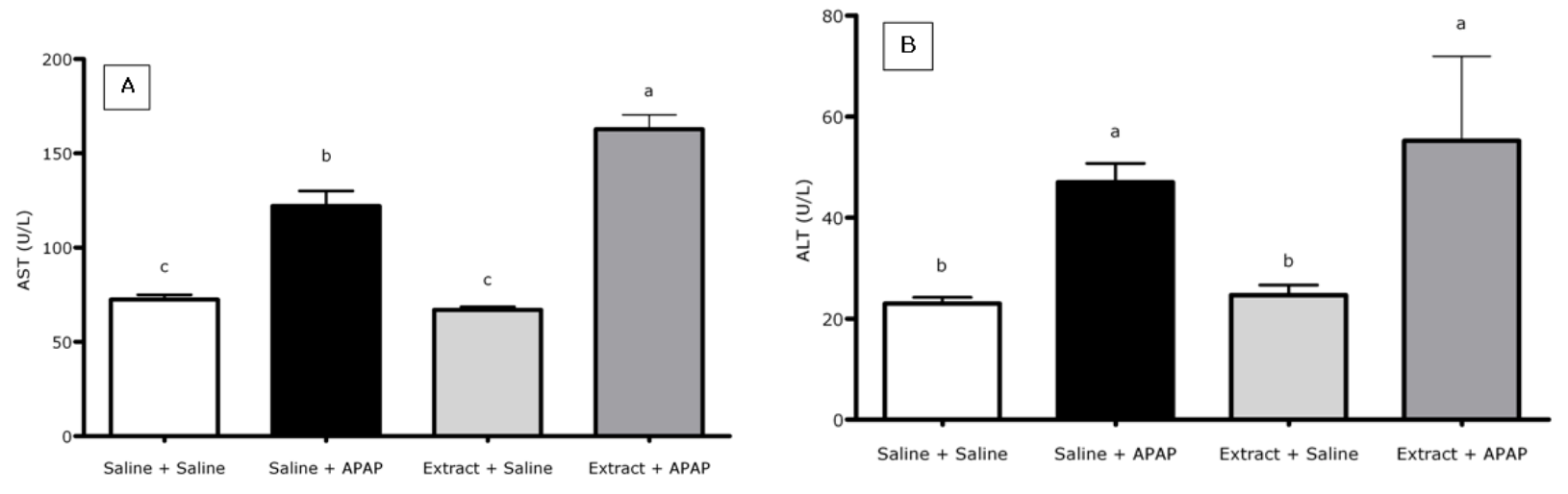

Figure 3 - Aspartate aminotransferase (AST) (A) and alanine aminotransferase (ALT) (B) activity in the serum of rats pre-treated with $M$. officinalis $(500 \mathrm{mg} / \mathrm{kg})$ extract or saline and treated with acetaminophen (APAP, $800 \mathrm{mg} / \mathrm{Kg}$ ) or saline. Results are expressed as means and the vertical bars show the SEM. The different letters indicate significant differences $(\mathrm{P}<$ $0.05)$.

Although the levels of AST and ALT in the serum were increased in the animals treated with the APAP, histopathological analysis did not show the presence of necrosis in the centrolobular region of the hepatic parenchyma, indicating that the increase in the serum levels of transaminases could not always be histologically certified (data not shown).

The GGT comparison between the extract + saline $(2.5 \pm 1.2 \mathrm{mU} / 24 \mathrm{~h})$ and the saline + saline group $(4.6 \pm 3.9 \mathrm{mU} / 24 \mathrm{~h})$ showed no differences, suggesting that the extract was not nephrotoxic (Fig.4). Urine levels of GGT increased in the saline + APAP group $(268.7 \pm 98.8 \mathrm{mU} / 24 \mathrm{~h})$ compared with the saline + saline group, indicating that the APAP was nephrotoxic.

Although the levels of GGT were high in the animals pre-treated with the extract + APAP $(74.7 \pm 23.0 \mathrm{mU} / 24 \mathrm{~h})$, they were significantly lower $(\mathrm{P}<0.05)$ than those observed in the saline + APAP group and showed no differences from the saline + saline group (Fig. 4).

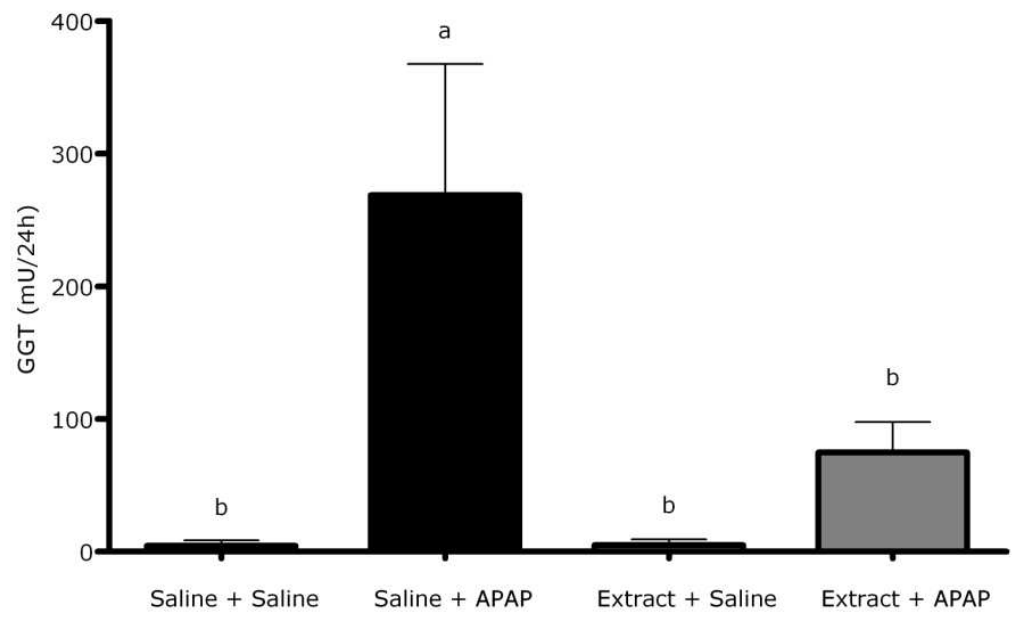

Figure 4 - $\gamma$-glutamyltransferase (GGT) activity in the urine of rats pre-treated with of $M$. officinalis $(500 \mathrm{mg} / \mathrm{kg}$ ) extract or saline and treated with acetaminophen (APAP, $800 \mathrm{mg} / \mathrm{Kg}$ ) or saline. Results are expressed as means and the vertical bars show the SEM. The different letters indicate significant differences $(\mathrm{P}<0.05)$. 


\section{DISCUSSION}

The extracts of $M$. officinalis at concentrations of 100 and $200 \mathrm{mg} / \mathrm{kg}$ resulted in the reduction in the volume of the pleural exudate, and in the levels of both leukocytes and polymorphonuclear cells. However, the reduction in total proteins occurred only in the animals in the group pre-treated with the concentration of the extract at $200 \mathrm{mg} / \mathrm{kg}$. These results indicated an anti-inflammatory response. At the same time, $50 \mathrm{mg} / \mathrm{kg}$ of extract showed no anti-inflammatory effect. Curcumin and other polyphenols may inhibit arachidonic acid metabolism, reducing the production of proinflammatory metabolites such as certain prostaglandins (Yang et al. 2001). Oil from Ocimum sanctum seeds can inhibit the enhancement of vascular capillary permeability and leukocyte migration following an inflammatory stimulus (Singh et al. 2007). The extracts of Rosmarinus officinalis showed a dosedependent response with an anti-inflammatory activity similar to that observed with indomethacin, a nonsteroidal anti-inflammatory drug (Altinier et al. 2007). Other species of Lamiaceae, such as Perilla frutescens, Salvia leriifolia and Leonitis leonurusi also showed antiinflammatory activity (Hosseinzadeh et al. 2003; Osakabe 2004). Tanetin, a lipophilic flavonol extracted from Tanacetum parthenium inhibited eicosanoids, a derivative of arachidonic acid, suggesting an anti-inflammatory action (Williams et al. 1995). The same occurred with other flavonoids, which inhibited cyclooxygenase, monooxygenase and lipooxygenase through the metabolism of arachidonic acid (Svobodová et al. 2003). Cyclooxygenase-2 (COX-2) may display a pro-inflammatory activity in the first phase of carrageenan-induced pleurisy, in which polymorphonuclear cells predominate, which is followed by a phase during which there is antiinflammatory activity, when mononuclear cells predominate (Derek et al. 1999). Rosmarinic acid, found in all the members of the family Lamiaceae, displays anti-inflammatory action, inhibiting monocyclooxygenase, lipooxygenase and cyclooxygenase (Janicsák et al. 1999).

The extracts of $M$. officinalis contain phenolic compounds, such as quercetin and rosmarinic acid, which show anti-inflammatory properties and antioxidant action (Svobodová et al. 2003; Marongiu et al. 2004). The present results suggested that there was a dose-response effect in relation to the concentrations of the extracts and the inflammation markers evaluated.

Results showed that the administration of APAP resulted in an increase in the serum levels of both AST and ALT. The APAP hepatotoxicity could be characterized by an increase in the levels of AST and ALT, due to both centrolobular necrosis and hemorrhage (Ito et al. 2004). Similar to what occurs in the liver, the APAP is metabolized by the $\mathrm{P} 450$ cytochrome in the kidney, producing an intermediary cytotoxin (NAPQI), which is a free radical (Bessems and Vermaulen 2001) that is rapidly conjugated by glutathione (GSH). GSH depletion, either hepatic or renal, leads to APAP cytotoxicity (Stern et al. 2005).

Acute starving in the rats may cause an increase in the hepatotoxicity of APAP. This effect has been related to the reductions in the hepatic GSH levels and in the conjugation capacity of APAP with glucuronide and sulfate (Price et al. 1987). Considering this, more APAP is metabolized by P450, resulting in the increase of NAPQI production.

Although it has been shown that the extracts of $M$. officinalis contain high levels of phenolic compounds and flavonoids, and that they have no hepatotoxic effect, the extracts did not protect the liver or kidneys against injury, as has been reported for other species of Lamiaceae (Samarth et al. 2006; El-Ashmawy et al. 2005; Galisteo et al. 2006). Phenolic compounds are considered chemopreventive agents because they induce phase II enzymes, such as glutathione $S$ transferase, which is involved in the detoxification of xenobiotics. In addition, it has been reported that most phenolics exhibit an important prooxidant effect, especially when tissue injury causes the release of free iron or copper (Yang et al. 2001). Intriguingly, the intragastric dose of the extract + APAP resulted in a higher serum AST, indicating a rise in toxicity. However, there was no observed difference between the extract + saline group and the saline group, indicating that the extract was not hepatotoxic. The increase in the toxicity of the extract + APAP was an unexpected observation. This could likely result from the prooxidant effect on the injured liver. Besides the direct biological effects of the polyphenols, simultaneous administration of the drugs and these compounds could induce the pharmacokinetic alterations in the drugs, leading to an increase in the toxicity or diminishing the therapeutic effects. 
Dietary phenolics have been shown to act as prooxidants in the systems containing redox-active metals, leading to the formation of reactive oxygen species and phenoxyl radicals (Decker 1997). In the presence of $\mathrm{O}_{2}$, transition metals such as $\mathrm{Cu}$ and $\mathrm{Fe}$ catalyze the redox cycling of phenolics, leading to the formation of reactive oxygen species and other organic radicals that can damage the DNA, lipids, and other biological molecules (Sakihama et al. 2002). Considering the effect of APAP in inducing the hepatic necrosis and the presence of high levels of iron and copper stored in the liver, the increase in the toxicity of the extract + APAP could be related to the presence of extracellular copper and iron released by the lesioned liver, leading to increased pro-oxidant and hepatotoxic effects of the extracts.

The administration of the drugs along with the phenolics might also induce the pharmokinetic alterations in the drugs, which could lead to an increased toxicity or a diminished therapeutic effect. Polyphenols, such as tannic acid, increased the activity of glutathione S-transferase in the kidney, but reduced the activity of this enzyme in the liver, modulating the enzymes involved in detoxification pathways. Pyrogallol, a simple phenolic found in green tea, was shown to cause significant hepatic damage in the rats when administered intraperitoneally (Decker 1997). There is limited information on the P450-mediated intracellular metabolism of the flavonoids and phenolics, especially when these compounds are administered as crude extracts. Several species of the medicinal plants display hepatoprotection. The extracts of Origanum majorana reduced the levels of AST and ALT in the mice exposed to lead (ElAshmawy et al., 2005). Studies with the extracts of Rosmarinus tomentosus and $R$. officinalis showed a protective effect against hepatic injury and promoted cell integrity (Galisteo et al. 2006; Sotelo-Félix et al. 2002).

The renal tissue is the main source of the excreted urinary enzymes, and the evaluation of the GGT level is known to be a good and sensitive noninvasive method to measure the integrity of tubular cells (Price 1982). Pre-treatment with $500 \mathrm{mg} / \mathrm{kg}$ of extract reduced the GGT levels after APAP administration, indicating a protective effect of this plant species. Moreover, the extracts of $M$. officinalis showed no nephrotoxic activity. APAP administration led to an increase in the GGT levels in urine. This toxic effect might be attributed to the renal cytochromes P450, similarly to the effect observed in the liver. Although the acute renal lesion does not always occur simultaneously with the hepatic lesion, renal GSH depletion leads to APAP cytotoxicity (Stern et al. 2005), which can be characterized by an increase of GGT in the urine levels (Lee et al. 2002).

The data obtained in the present study suggested that the extract was not hepatoprotective and could lead to an increase in the lesions induced by APAP. On the other hand, the extract was nephroprotective against the lesions induced by APAP and showed an anti-inflammatory effect on pleurisy carrageenan-induced. These results might help in clarifying the great clinical relevance of the aqueous extract of $M$. officinalis in elucidating its role as an anti-inflammatory agent.

\section{REFERENCES}

Akdogan M, Kilmc I, Oncu M, et al. Investigation of biochemical and histopathological effects of Mentha piperita L. and Mentha spicata L. on kidney tissue in rats. Hum. Exp. Toxicol. 2003; 22: 213-219.

Altinier G, Sos S, Aquino RP, et al. Characterization of topical antiinflamatory compounds in Rosmarinus officinalis L. J. Agricult. Food Chem. 2007; 55: 17181723.

Bessems JGM, Vermeulen NPE. Paracetamol (acetaminophen)-induced toxicity: molecular and biochemical mechenisms, analogues and protective approaches. Crit. Rev. Toxicol. 2001; 31: 55-138.

Boschi ES, Leite CE, Saciura VC, et al. Antiinflammatory effects of low-level laser therapy $(660 \mathrm{~nm})$ in the early phase in carrageenan-induced pleurisy in rat. Lasers in Surgery and Medicine 2008; 40: 500-508.

Carnat AP, Carnat A, Fraisse D, et al. The aromatic and polyphenolic composition of lemon balm (Melissa officinalis L. subsp. officinalis) tea. Pharm. Acta Helv. 1998; 72: 301-305.

Decker EA. Phenolics: prooxidants or antioxidants? Nutr. Rev. 1997; 55: 396- 407.

Derek W, Gilroy PR, Colville-Nash D, et al. Inducible cyclooxygenase may have anti-inflammatory properties. Nat. Med. 1999; 5: 698-701.

El-Ashmawy IM, El-Nahas AF, Salama OM. Protective effect of volatile oil, alcoholic and aqueous extracts of Origanum majorana on lead acetate toxicity in mice. Basic Clin. Pharnmacol. Toxicol. 2005; 97: 238-243.

Galati G, O'brien PJ. Flavonoids and isoflavones (phytoestrogens): absorption, metabolism, and bioactivity. Free Radic. Biol. Med. 2004; 37: 287303. 
Galisteo M, Suárez A, Montilla MP, et al. Protective effects of Rosmarinus tomentosus ethanol extract on thioacetamide-induced liver cirrhosis in rats. Phytomedicine 2006; 13: 101-108.

Garlet TMB, Irgang BE. Plantas medicinais utilizadas na medicina popular por mulheres trabalhadoras rurais de Cruz Alta, Rio Grande do Sul, Brasil. Rev. Bras. Pl. Med. 2001; 4: 9-18.

Hosseinzadeh H, Haddadkhodaparast MH, Arash AR. Antinocipective, antiinflamatory anda cute toxicity effects of Salvia leriifolia Benth seed extract in mice and rats. Phytother. Res. 2003; 17: 422-425.

Ito Y, Abril E, Bethea NW, et al. Role of nitric oxide in hepatic microvascular injury elicited by acetaminophen in mice. Am. J. Physiol. Gastrointest. Liver Physiol. 2004; 286: G60-G67.

Janicsák G, Máthé I, Miklóssy-Vári V, et al. Comparative studies of the rosmarinic and cafeic acid contents of Lamiaceae species. Biochem. Syst. Ecol. 1999; 27: 733-738.

Lee SC, Tsai CC, Chen JC, et al. Effects of "Chinese yam" on hepato-nephrotoxicity of acetaminophen in rats. Acta Pharmacol. Sin. 2002; 23: 503-508.

Lin C, Huang PC, Lin JM. Antioxidant and hepatoprotective effect of Anoectochilus formosanus and Gynostemma pentaphyllum. Am. J. Chin. Med. 2000; 28: 87-96.

Lopes RP, Lunardelli A, Preissler T, et al. The effects of fructose-1,6-bisphosphate and dexamethasone on acute inflammation and $\mathrm{T}$-cell proliferation. Inflammation Research 2006; 55: 354-358.

Lunardelli A, Leite CE, Pires MGS, et al. Extract of the bristles of Dirphia sp. increases nitric oxide in a rat pleurisy model. Inflammation Research 2006; 55: 129-135.

Marongiu B, Porcedda S, Piras A, et al. Antioxidant activity of supercritical extract of Melissa officinalis subsp. officinalis and Melissa officinalis subsp. inodora. Phytother. Res. 2004; 18: 789-792.

Oniga I, Pârvu AE, Toiu A, et al. Effects of Salvia officinalis L. extract on experimental acute inflammation. Rev. Med. Chir. Soc. Med. Nat. Iasi. 2007; 111: 290-294.

Osakabe N, Yasuda A, Natsume M, et al. Rosmarinic acid inhibits epidermal inflammatory responses: anticarcinogenic effect of Perilla frutescens extract in the murine two-stage skin model. Carcinogenesis 2004; 25: 549-557.

Paul EL, Lunardelli A, Caberlon E, et al. Antiinflammatory and immunomodulatory effects of Baccharis trimera aqueous extract on induced pleurisy in rats and lymphoproliferation in vitro. Inflammation 2009; 32: 419-425.

Petersen M, Simmonds MSJ. Rosmarinic acid. Phytochemistry 2003; 62: 121-125.

Price RG. Urinary enzymes, nephrotoxicity and renal disease. Toxicology, 1982; 23: 99-134.
Price VF, Miller MG, Jollow DJ. Mechanisms of fasting-induced potentiation of acetaminophen hepatotoxicity in the rat. Biochem. Pharmacol. 1987; 36: 427-433.

Sakihama Y, Cohen MF, Grace SC, et al. Plant phenolic antioxidant and prooxidant activities: phenolicsinduced oxidative damage mediated by metals in plants. Toxicology 2002; 177, 67-80.

Samarth RM, Panwar M, Kumar M, et al. Radioprotective influence of Mentha piperita (Linn) against gamma irradiation in mice: Antioxidant and radical scavenging activity. Int. J. Radiat. Biol. 2006; 82: 331-337.

Santos RCV, Lunardelli A, Caberlon E, et al. Antiinflammatory and immunomodulatory effects of Ulomoides dermestoides on induced pleurisy in rats and lymphoproliferation in vitro. Inflammation 2010; 33: 173-179.

Schumann G, Bonora R, Ceriotti F, et al. IFCC primary reference procedures for the measurement of catalytic activity concentrations of enzymes at $37^{\circ} \mathrm{C}$. Part 4 . Reference procedure for the measurement of catalytic concentration of alanine aminotransferase. Clin. Chem. Lab. Med. 2002a; 40: 718-724.

Schumann G, Bonora R, Ceriotti F, et al. IFCC primary reference procedures for the measurement of catalytic activity concentrations of enzymes at $37^{\circ} \mathrm{C}$. Part 5 . Reference procedure for the measurement of catalytic concentration of aspartate aminotransferase. Clin. Chem. Lab. Med. 2002b; 40: 725-733.

Schumann G, Bonora R, Ceriotti F, et al. IFCC primary reference procedures for the measurement of catalytic activity concentrations of enzymes at $37^{\circ} \mathrm{C}$. Part 6 . Reference procedure for the measurement of catalytic concentration of $\gamma$-Glutamyltransferase. Clin. Chem. Lab. Med. 2002c; 40: 734-738.

Schumann G, Canalias F, Joergensen PJ, et al. IFCC reference procedures for measurement of the catalytic concentrations of enzymes: corrigendum, notes and useful advice. Clin. Chem. Lab. Med. 2010; 48: 615621.

Silberberg M, Besson C, Manach C, et al. Influence of dietary antioxidants on polyphenol intestinal absorption and metabolism in rats. J. Agric. Food Chem. 2006; 28: 3541-3546.

Singh S, Taneja M, Majumdar DK. Biological activities of Ocimum sanctum L. fixed oil - an overview. Indian J. Exp. Biol. 2007; 45: 403-412.

Sotelo-Félix JI, Martinez-Fong D, Muriel P, et al. Evaluation of the effectiveness of Rosmarinus officinalis (Lamiaceae) in the alleviation of carbon tetrachloride-induced acute hepatotoxicity in the rat. J. Ethnopharmacol. 2002; 81: 145-154.

Spiller F, Alves MK, Vieira SM, et al. Antiinflammatory effects of red pepper (Capsicum baccatum) on carrageenan- and antigen-induced inflammation. Journal of Pharmacy and Pharmacology 2008; 60: 473-478. 
Stern ST, Bruno MK, Hennig GE, et al. Contribution of acetaminophen-cysteine to acetaminophen nephrotoxicity in CD-1 mice: I. Enhancement of acetaminophen nephrotoxicity by acetaminophencysteine. Toxicol. Appl. Pharmacol. 2005; 202: 151159.

Svobodová A, Psotová J, Walterová D. Natural phenolics in the prevention of UV-induced skin damage. Biomed. Pap. Med. Fac. Univ. Palacky Olomouc. Czech. Repub. 2003; 147: 137-145.

Yang CS, Landau JM, Huang M-T, et al. Inhibition of carcinogenesis by dietary polyphenolic compounds. Annu. Rev. Nutr. 2001; 21: 381-406.
Williams CA, Hoult JRS, Harborne JB, et al. A biologically active lipophilic flavonol from Tanacetum parthenium. Phytochemistry 1995; 38: 267-270.

Received: November 08, 2011; Revised: November 26, 2012; Accepted: February 15, 2013. 